\title{
Piqueteros en "el gran diario argentino". \\ Las representaciones de Clarín en un periodo de crisis de hegemonía
}

\section{Piqueteros in "the great Argentine newspaper". Clarín representations in a period of crisis of hegemony}

doi: http://dx.doi.org/10.32870/

espiral.v24i68.4780

\section{Resumen}

En este artículo se examina la evolución de los discursos más difundidos en Argentina sobre el movimiento piquetero entre 2000 y 200 I, un periodo de crisis de hegemonía. Para eso, con base en una estrategia teóricometodológica que sigue los principales aportes del análisis crítico del discurso, se analizan las noticias publicadas en el diario con mayor difusión con relación a un caso paradigmático: el de los cortes de ruta y las rebeliones populares protagonizadas por el movimiento piquetero en la provincia de Salta. El trabajo muestra la relación compleja y contradictoria que existe entre el desarrollo de la crisis de hegemonía y las representaciones desplegadas en Clarín.

Palabras clave: piqueteros, puebladas, Salta, representaciones mediáticas, Clarín.

\author{
José Daniel Benclowicz*
}

\begin{abstract}
This paper examines the evolution of the most widespread discourses in Argentina about the piqueteros movement between 2000 and $200 \mathrm{I}$, a period marked by the development of a crisis of hegemony. For that, based on theoretical and methodological strategy that follows the main contributions of critical discourse analysis, the news published in the newspaper with the highest circulation are analyzed in relation to a case in point: the roadblocks and popular rebellions starred by piqueteros movement in the province of Salta. The article shows the complex and contradictory relationship between the development of the crisis of hegemony and the representations deployed in Clarin.
\end{abstract}

Keywords: piqueteros, popular rebellions, Salta, media representations, Clarín.

-Investigador Adjunto del Consejo Nacional de Investigaciones Científicas y Técnicas (CONICET), y Profesor Adjunto Regular de la Universidad Nacional de Río Negro (UNRN), Argentina. jd.benclowicz@gmail.com

Fecha de recepción: 18 de diciembre de 2015. Fecha de aceptación: 22 de agosto de 2016. 
Introducción'

La segunda mitad de la década de 1990 constituyó un periodo de creciente multiplicación de las luchas sociales en Argentina, que tuvo como uno de sus actores centrales al movimiento piquetero de trabajadores desocupados. ${ }^{2} \mathrm{La}$ masividad del novedoso movimiento y la radicalidad de sus métodos, que refiere a una situación socialmente desesperada y a la existencia de una dilatada experiencia de luchas y organización, entre otros elementos, favorecieron la conquista de una amplia visibilidad. Esta fue acompañada lógicamente por la construcción de representaciones destinadas a catalogar la novedad, que hacia finales de la década de 1990 se había extendido a lo largo y ancho del país.

Ese momento, que coincide con el ascenso del Gobierno de Fernando de la Rúa, aparece retrospectivamente como el del inicio de un proceso de agravamiento de la situación política y económica y de exacerbación de la lucha de clases que desembocó en el "argentinazo" del 19 y 20 de diciembre de 2001, la caída del presidente De la Rúa y la conformación de asambleas populares en las principales ciudades del país.

En el marco de este proceso de crisis de hegemonía (Gramsci, 2001), que redundó en la disolución de las bases consensuales del poder, ${ }^{3}$ se sitúa el presente trabajo. Se trata de analizar el modo en que fueron evolucionando

I. Este trabajo contó con el financiamiento de los proyectos PI UNRN 40-B-365 de la Universidad Nacional de Río Negro y PIP 0027 del Consejo Nacional de Investigaciones Científicas y Técnicas (CONICET).

2. El nombre de este masivo movimiento refiere al "piquete", palabra que se empezó a utilizar a partir de la segunda mitad de la década de 1990 para aludir al corte de rutas y otras vías de comunicación protagonizadas por los desempleados. Su nexo con el piquete obrero en defensa de las huelgas, consistente en el corte de acceso a las empresas y establecimientos, es un indicador de la continuidad de una cultura obrera combativa que se manifestó bajo nuevas formas en el contexto de la desocupación masiva de los años noventa.

3. La consigna "iQue se vayan todos!" (los políticos), ampliamente difundida por entonces, expresa en forma sintética y cabal esa disolución. 
los discursos más difundidos sobre uno de los principales fenómenos de la lucha social entre finales de la década de 1990 y principios de la siguiente. Para eso, se utiliza como centro un caso altamente significativo: el de las rebeliones populares registradas en mayo de 2000, noviembre de 2000 y junio de 2001 en las localidades salteñas de Tartagal y General Mosconi. Estas protestas, que tuvieron al movimiento piquetero como principal protagonista, involucraron cortes de ruta que fueron reprimidos por las autoridades, generando fuertes choques entre las fuerzas de seguridad y los manifestantes y rebeliones populares masivas que desarrollaron ampliamente prácticas asamblearias y desconocieron a las autoridades locales.

El estudio se basa principalmente en un análisis en profundidad de la totalidad de las noticias publicadas en el diario Clarín -que cuenta con la mayor tirada a nivel nacional- referidas a esas tres rebeliones populares. A su vez, se contrasta ese corpus con el de los artículos informativos del diario El Tribuno, que debido a su anclaje provincial es el que mayor cobertura ofreció sobre los acontecimientos en cuestión. ${ }^{4}$

La estructura de medios de comunicación argentina -y en gran medida, latinoamericana-registró una transformación significativa durante los años noventa, cuando al calor de las medidas de desregulación económica de signo neoliberal se habilitó la posibilidad de propiedades cruzadas. Dadas las condiciones de concentración imperantes, esta modificación del marco legal dio lugar a la creación de los grupos multimedia (Mastrini y Becerra, 2006 y 2011). Ya antes de ese momento, "el gran diario argentino" -como reza un conocido eslogan de Clarín- no sólo era el periódico más

4. Clarín publicó veintisiete notas en mayo de 2000 , veintitrés en noviembre de ese mismo año y treinta y dos en junio de 200I. Por su parte, El Tribuno publicó noventa y cinco notas en mayo de 2000, cincuenta y siete en noviembre de 2000 y setenta y cinco en junio de 2001 . 
vendido del país, sino que se había convertido en un actor político central con una fluida relación con los Gobiernos en turno, lo que favoreció el crecimiento sistemático de su tirada e influencia en la sociedad (Sivak, 2013).

Sobre esa base, a partir de la década de 1990 el grupo Clarín se convirtió en el principal grupo multimedios de Argentina y uno de los más importantes de Latinoamérica, ${ }^{5}$ llegando a concentrar varios canales de televisión abierta en la capital y distintos puntos del país, varias señales y el principal sistema de distribución de televisión por cable y una importante cadena de radio, teniendo una participación dominante en agencias noticiosas, productoras audiovisuales, empresas de distribución de internet, y en la fabricación de papel para prensa. Esta presencia masiva en el mercado lo convirtió en uno de los grupos empresarios con mayor influencia del país, reforzando su papel como productor y reproductor de discursos hegemónicos, por lo que el análisis de los sentidos asignados a la impugnación piquetera del orden en un contexto de crisis de hegemonía resulta particularmente relevante.

Con base en una estrategia teórico-metodológica que sigue los principales aportes del análisis crítico del discurso (Benclowicz y Werenkraut, 2013), se aborda el examen de las noticias tanto en sus aspectos formales como de contenido, teniendo en cuenta que la construcción de los acontecimientos por parte de la prensa tiene un carácter necesariamente ideológico que determina una codificación específica de los hechos a los que se alude (Van Dijk, 1990 y 2008; Fairclough, 1993; Verón, 1993).

$\mathrm{Al}$ igual que otros acontecimientos, los conflictos sociales implican una disputa asociada al sentido de las acciones, lo cual incide a su vez en el curso y resultado de las mismas. Así, es de esperar que existan discursos tendientes a reivin-

\footnotetext{
5. Junto al brasileño Globo, el mexicano Televisa y el venezolano Cisneros.
}

\section{4}


dicar determinadas acciones colectivas o ciertos aspectos de las mismas, y otros proclives a minar su legitimidad. Entre los discursos hegemónicos que dan cuenta de los conflictos sociales, el de los medios masivos de comunicación ocupa un lugar central, ya que proporciona representaciones e interpretaciones a través de las cuales los distintos sectores y clases sociales conocen y piensan sus prácticas y las de los demás como parte de una totalidad (Hall, 1981).

Por su parte, el análisis cualitativo y cuantitativo del conjunto de noticias sobre conflictos sociales diferenciados registrados en un mismo espacio permite estudiar la evolución de unas estrategias discursivas que, en la medida en que inciden en el desenlace de los acontecimientos al tiempo que son influidas por estos, constituyen un capítulo importante de la dinámica de la lucha de clases.

En función de lo expuesto hasta aquí, se organizó el artículo de la siguiente manera. En el primer apartado se pasa revista al proceso de luchas registrado en las localidades de Tartagal y Mosconi entre mayo de 2000 y junio de 2001; en el segundo, se examinan cuestiones formales como el tamaño, el momento y la sección donde son publicadas las noticias, lo que permite un primer acercamiento a las representaciones de los acontecimientos; en el tercero se analiza la evolución del contenido de las noticias desde un punto de vista general, considerando qué voces aparecen en los textos y cómo se explica causalmente la protesta; en el cuarto se indaga en torno a las distintas representaciones propuestas por los discursos teniendo en cuenta el momento en que se formularon y se evalúan los artículos periodísticos de acuerdo a su posición predominante. En la última sección se exponen las conclusiones, que sintetizan la relación compleja y contradictoria que existe entre el desarrollo de la crisis de hegemonía y las representaciones desplegadas en Clarín. 
El proceso de luchas en Tartagal y Mosconi

Las puebladas ${ }^{6}$ registradas en la zona entre mayo de 2000 y junio de 2001 forman parte de un proceso de luchas más amplio, que se puede remitir por lo menos a la privatización de la empresa estatal Yacimientos Petrolíferos Fiscales (YPF), a principios de la década de 1990. Esta medida principió un amplio programa de contrarreformas de orientación neoliberal impulsado por el Gobierno de Carlos Saúl Menem (1989-1999). YPF resultaba central económica y socialmente en localidades como Tartagal y Mosconi, y su privatización generó importantes resistencias antes y después de la emergencia del movimiento piquetero.

Los principales antecedentes del proceso de lucha de 2000-2001 a nivel local fueron las puebladas de septiembre de 1991 y de mayo de 1997, la primera contra la privatización de YPF, la segunda contra sus efectos sociales, que se tornaron insostenibles por ese entonces. La rebelión popular de 1997 sostuvo un bloqueo comunitario de la ruta nacional 34 durante siete días, a lo largo de los cuales se desarrollaron asambleas populares masivas en cuyo seno se conformó el movimiento de trabajadores desocupados de la zona (Benclowicz, 2011a y 2013). La protesta fue desactivada después de fuertes amenazas de desalojar la ruta por la fuerza y del otorgamiento por parte de los Gobiernos nacional y provincial de un número importante de planes sociales, entre otras concesiones que fueron cumplidas sólo parcialmente y dieron lugar, entre otras razones, al proceso de lucha aquí tratado.

A finales de 1999, en un contexto de resquebrajamiento de la hegemonía neoliberal que predominó durante los años noventa (Bonnet, 2008; Piva, 2012), se produjo un recambio 
político a nivel nacional con el ascenso del Gobierno de la Alianza UCR-FrePaSo. El Gobierno aliancista generó en un principio expectativas de cambio significativas en la orientación de las políticas socioeconómicas, que no tardó en contradecir. Además de sostener sin alteraciones las políticas de ajuste previas, redujo significativamente la cantidad de planes sociales. A eso se le agregaron en Tartagal y Mosconi la falta de pago de haberes para desocupados y empleados municipales y amenazas de desalojo por falta de pago de alquileres.

En ese contexto, fue madurando un clima de agudo descontento y el 02 de mayo de 2000 trabajadores desocupados iniciaron un nuevo corte de ruta, concitando un creciente apoyo de la población local. Después de diez días de bloqueo se produjo la represión, que derivó en intensos enfrentamientos en la ruta y en el pueblo de Mosconi, a donde la Policía de la provincia ingresó en busca de los manifestantes, utilizando gases lacrimógenos y balas de goma y de plomo.

Ese hecho provocó un estallido popular que superó en envergadura y profundidad a los que ya se habían producido en la zona. La población de Mosconi se volcó a las calles, la comisaría local fue tomada y la policía, superada varias veces en número, debió retirarse del pueblo. En ese contexto, se produjeron distintos ataques a la Municipalidad y a un cajero automático del banco local, símbolos del poder político y económico. Poco después, los pobladores se encaminaron hacia la ruta. Mientras tanto, desde Tartagal, cerca de 20000 personas se dirigieron a Mosconi para unirse a otros manifestantes, y las fuerzas represivas fueron obligadas a retroceder. Si se considera que la población total de Tartagal y de Mosconi ascendía a 60585 y 19811 habitantes, respectivamente (INDEC, 2001), se puede advertir la masividad de la pueblada.

La ruta quedó bajo el control de los manifestantes, quienes tras deliberar en asamblea elaboraron un extenso 
pliego de reclamos. El petitorio definitivo tenía treinta y un puntos; algunos recuperaban lo acordado e incumplido desde la última pueblada; otros, como la exigencia de 15000 puestos de trabajo genuino, iban más lejos. Finalmente, tras una larga negociación entre los representantes de los manifestantes y de los Gobiernos nacional y provincial que se extendió a lo largo de la noche del 13 y la madrugada del 14 de mayo, en la que fueron concedidos numerosos reclamos, la protesta fue levantada (Oviedo, 2001; Svampa y Pereyra, 2003).

El 30 de octubre de 2000 se inició un nuevo corte de la ruta nacional 34 a la altura de Tartagal. Al incumplimiento en general por parte del poder político de lo acordado en los conflictos anteriores, se sumaron en esta ocasión la disminución del estipendio y de la cantidad de planes sociales, el despido de trabajadores de una contratista de la empresa de electricidad, la Empresa de Energía de Salta (EDESA), y de la empresa de transportes Atahualpa. Por último, las comunidades indígenas se organizaron para reclamar la participación en los programas de ayuda social de la provincia y la titularización de tierras.

La protesta se produjo en un contexto nacional caracterizado por una notable crisis política y un alza de las luchas, especialmente de los cortes de ruta. La crisis política derivó en el mes de octubre en la renuncia del vicepresidente Carlos Álvarez, principal referente del FrePaSo. Por otra parte, a principios de noviembre llegaron a producirse catorce bloqueos de rutas protagonizados principalmente por trabajadores ocupados y desocupados. Entre los piquetes más importantes se contaban los de Salta, Neuquén, Jujuy, Catamarca, Chaco y varias localidades de la provincia de Buenos Aires; el de mayor envergadura se desarrollaba en La Matanza.

El 10 de noviembre, poco antes del amanecer, la Policía de la provincia avanzó sobre el corte de Salta y mató a 
Aníbal Verón, un extrabajador de la empresa Atahualpa que había sido despedido un año antes y a quien se le adeudaban varios meses de sueldo. La represión y el asesinato de Verón terminaron por desencadenar sendas puebladas en ambas localidades. En Mosconi, donde los símbolos del poder político y económico habían sido arrasados en mayo, fue tomada la comisaría y cuatro policías fueron tomados de rehenes. El grueso de los manifestantes se reagrupó en la ruta y avanzó hacia Tartagal. La policía se replegó rápidamente y se refugió en el regimiento 28, del Ejército.

La noticia del asesinato de Verón se conoció por la mañana, y para ese momento a los manifestantes originales se sumaron muchos más, que recorrieron las calles céntricas de Tartagal atacando en primer término los edificios públicos. La comisaría fue tomada, destruida y finalmente incendiada; también fueron atacados la Municipalidad, el Banco Nación y la sede municipal de Acción Social. Además de estos y otros edificios públicos, los manifestantes destruyeron la corresponsalía del diario El Tribuno -propiedad del gobernador Juan Carlos Romero-, las sedes de EDESA y de Atahualpa, y la oficina de un diputado del Partido Justicialista (PJ). Por la tarde, cuando el grueso de los piqueteros había regresado a la ruta y reinstalado los piquetes, se produjeron saqueos selectivos a dos comercios tartagalenses y al depósito judicial, de donde fueron extraídas distintas armas.

Diversos informantes, incluyendo los sectores empresariales afectados, coincidieron en desligar a las organizaciones de desocupados de estos últimos hechos, vinculando al poder político provincial y local. Sin embargo, los saqueos y la sensación de descontrol habían dividido a la comunidad, y el corte fue levantado el día 13, tras la firma de un acuerdo que implicaba un compromiso menor con respecto a los que habían asumido las autoridades previamente (Benclowicz y Artese, 2011). 
Tras el levantamiento del corte, las organizaciones de desocupados conformaron la Coordinadora de Trabajadores y Desocupados, que desplegó una importante actividad. Una de sus acciones más destacadas fue la instalación de piquetes sobre las compañías petroleras y contratistas de servicios para lograr la incorporación de personal y aumentos de salarios. La coordinadora se perfiló como eje de reagrupamiento del movimiento obrero local, planteando la acción conjunta de los trabajadores ocupados y desocupados, y se convirtió en una interlocutora ineludible para las empresas a la hora de incorporar personal y negociar salarios. El movimiento piquetero de Tartagal-Mosconi estaba en alza, en un contexto nacional en el que la crisis económica y política a nivel nacional y provincial se aceleraba y las movilizaciones populares se multiplicaban. En marzo de 2001 renunciaron dos ministros de Economía -José Luis Machinea y Ricardo López Murphy, que permaneció apenas una semana en el puesto-, y asumió el cargo Domingo Cavallo, que lo había ocupado durante el mandato de Menem.

En mayo, los obreros que estaban construyendo el hospital de Mosconi -que habían conseguido ese trabajo a partir de la lucha piquetera- declararon una huelga con el apoyo de las organizaciones de desocupados exigiendo aumento de salarios, lo que derivó en un nuevo corte de ruta. A los pocos días de establecido el bloqueo, la justicia ordenó la captura de distintos dirigentes piqueteros y de partidos de izquierda acusados de corte de ruta, sedición y ejercer la democracia semidirecta, en referencia a los piquetes y a la resistencia a la represión y las asambleas populares realizadas en las protestas previas.

Ante la detención de distintos dirigentes, el movimiento respondió convocando a un paro general en todo el departamento para el 05 de junio, y fortaleció los piquetes. Después de casi tres semanas de corte, el 17 de junio la gendarmería atacó sorpresivamente a los manifestantes. 
El Gobierno difundió en los medios que había piqueteros armados y francotiradores, a partir de lo cual se justificó la utilización de armas de fuego por parte de las fuerzas represivas. En esa línea, se difundió una versión que hacía parecer a los piqueteros como "subversivos", se denunció la intervención de activistas "perfectamente entrenados" y se sugirieron conexiones con las FARC colombianas y con Sendero Luminoso, de Perú. ${ }^{7}$

En el marco de esa atmósfera, la Gendarmería ingresó a Mosconi, disparando con munición de guerra y gases lacrimógenos y realizando allanamientos indiscriminados. Mientras tanto, una importante cantidad de pobladores se congregó en la plaza del pueblo. Los habitantes de Tartagal se solidarizaron con sus vecinos e, incluso, los gendarmes que sufrieron heridas debieron ser trasladados porque los enfermeros del hospital de Tartagal se negaron a atenderlos.

En esa instancia, signada por la multiplicación de marchas, cortes de ruta, protestas y pronunciamientos de repudio a la represión y al Gobierno en todo el país, las autoridades se vieron forzadas a moderar las acciones de la gendarmería. La represión había causado dos muertes, decenas de heridos de bala y de detenidos, muchos de los cuales, según se denunció, sufrieron golpizas, distintos tipos de torturas -incluida la picana eléctrica-y simulacros de fusilamiento (Díaz Muñoz, 2005). La escalada represiva expresaba el nivel que alcanzaba para entonces la crisis de hegemonía en curso. Esto último también se manifestaba en los resultados de los comicios de octubre de 2001: el voto en blanco y nulo superó el $22 \%$, y el ausentismo fue mayor al $27 \%$. La alianza gobernante y el PJ, principal partido de

7. Más adelante, un jefe de Gendarmería reconoció que los únicos extranjeros que encontraron en la zona eran ejecutivos de empresas petroleras, y el juez de la causa, a su vez, que las personas detenidas no portaban armas, lo que indica la falsedad de esas versiones. 
oposición, obtuvieron entre ambos tan sólo el 31.6\% de votos del padrón (Ministerio del Interior, 2001).

A diferencia de las puebladas anteriores, en 2001 no se registró un acuerdo que pusiera fin al conflicto; la protesta persistió con un carácter defensivo y se fue diluyendo lentamente. Por otra parte, el 24 de julio se realizó la Primera Asamblea Piquetera Nacional, que reunió por primera vez, en la localidad bonaerense de La Matanza, a organizaciones de todo el país. La asamblea impulsó un combativo plan de lucha. Esas luchas presionaron y contribuyeron a la liberación de los dirigentes piqueteros salteños, a pesar de la gravedad de los cargos que enfrentaban.

Dos meses después de la Primera Asamblea Nacional Piquetera, en septiembre de 2001, se realizó la segunda, y el movimiento se consolidó en la mayor parte del país, convirtiéndose en una fuerza de oposición clave al régimen. Para ese entonces, la Coordinadora de Trabajadores y Desocupados del norte de Salta se había disuelto (Benclowicz, 2011b).

Visto el proceso en conjunto, la pueblada de 2001 cerró un ciclo en la historia de las luchas de la región, al tiempo que principió un alza de estas a nivel nacional, que alcanzó su punto más alto en diciembre de 2001 con la caída del Gobierno aliancista de Fernando de la Rúa, tras una semana de movilizaciones de amplios sectores sociales, cortes de rutas, saqueos, ataques a edificios públicos, bancos y empresas privatizadas, cacerolazos y combates callejeros (Iñigo Carrera y Cotarelo, 2006).

\section{Momento y lugar de las representaciones}

Las acciones de lucha registradas en Tartagal y Mosconi que se sintetizaron en el apartado anterior llegaron a constituirse en el centro de la agenda mediática, dando lugar al despliegue de un conjunto de representaciones sobre

\section{2}


las acciones y sus protagonistas, distribuidas en distintos artículos informativos que conforman el corpus del presente trabajo.

En las protestas del año 2000, es posible identificar tres periodos claramente diferenciados: el primero comprende los días transcurridos entre el comienzo del corte y el momento previo a la represión; el segundo se inicia con la represión y se extiende hasta el momento de la firma del acuerdo de los manifestantes con las autoridades; y el tercero es el que se abre con la resolución temporaria del conflicto; de este último se considera aquí el día posterior al acuerdo. Para el conflicto de junio de 2001 sólo se pueden establecer con claridad los dos primeros, ya que, como se dijo, no hay una resolución puntual. La ubicación de las noticias según periodos permite identificar el modo en que se fueron modificando las representaciones en función de los acontecimientos y del momento de la lucha. El cuadro general de noticias considerando el periodo en que fueron publicadas es el que se muestra en el Cuadro 1.

Cuadro 1. Frecuencia de notas según conflicto, periodo y duración del periodo. Diarios Clarín y El Tribuno

\begin{tabular}{|l|r|r|r|r|r|r|r|r|}
\hline Diario y Protesta & \multicolumn{2}{l|}{$\mathbf{1}^{\circ}$ período } & \multicolumn{2}{l|}{$\mathbf{2}^{\circ}$ período } & \multicolumn{2}{l|}{$\mathbf{3}^{\circ}$ período } & \multicolumn{2}{|l|}{ Totales } \\
\hline & Notas & \multicolumn{1}{|l|}{ Dias } & Notas & Dias & Notas & \multicolumn{1}{l|}{ Dias } & Notas & Dias \\
\hline Clarín & & & & & & & & \\
\hline Mayo 2000 & 5 & 10 & 14 & 1 & 8 & 1 & $\mathbf{2 7}$ & $\mathbf{1 2}$ \\
\hline Noviembre 2000 & 6 & 10 & 14 & 3 & 3 & 1 & $\mathbf{2 3}$ & $\mathbf{1 4}$ \\
\hline Junio 2001 & 3 & 18 & 29 & 4 & 0 & 0 & $\mathbf{3 2}$ & $\mathbf{2 2}$ \\
\hline El Tribuno & & & & & & & & \\
\hline Mayo 2000 & 48 & 10 & 34 & 1 & 13 & 1 & $\mathbf{9 5}$ & $\mathbf{1 2}$ \\
\hline Noviembre 2000 & 14 & 10 & 32 & 3 & 11 & 1 & $\mathbf{5 7}$ & $\mathbf{1 4}$ \\
\hline Junio 2001 & 17 & 18 & 58 & 4 & 0 & 0 & $\mathbf{7 5}$ & $\mathbf{2 2}$ \\
\hline
\end{tabular}

Fuente: elaboración propia con base en las ediciones de Clarín y $E l$ Tribuno (2000-2001).

Además del momento, es preciso tener en cuenta el lugar de las noticias, tanto en el sentido de la cantidad de espacio 
que ocupan -lo que determina la relevancia que le otorga el periódico- como en lo relativo a la ubicación específica de los artículos informativos dentro del diario. Como es de esperarse, el segundo periodo es el que concentra en las tres protestas y en los dos periódicos el mayor número de noticias de alta relevancia, que ocupan más de la mitad de página y muchas veces son publicadas en páginas impares. La elevada "noticiabilidad"8 de los acontecimientos registrados en el segundo periodo de las protestas explica satisfactoriamente este hecho.

En lo que se refiere a la ubicación específica de los artículos informativos, es preciso apuntar que en el caso de Clarín todas las noticias, sin importar el periodo, fueron publicadas en la sección "Política", lo cual indica una primera representación general de las protestas: no se trataron sólo de hechos policiales para el diario más influyente del país. Esta primera constatación no es una cuestión menor, habida cuenta de la tendencia a la criminalización de la protesta social que se aceleró desde finales de la década de 1990. Por su parte, El Tribuno tampoco ubicó sus artículos informativos sobre el tema en la sección "Policiales", sino en "Nacionales" o "Provinciales", dependiendo en general de la magnitud que cobrara el conflicto.

Dicho esto, en la Grafica 1 se muestra cómo se distribuyeron porcentualmente las noticias teniendo en cuenta los distintos periodos de la lucha.

8. Es decir, el interés que generara la noticia por su impacto. 
Gráfica 1. Frecuencia de notas por periodo en cada conflicto.

Diarios Clarín y El Tribuno

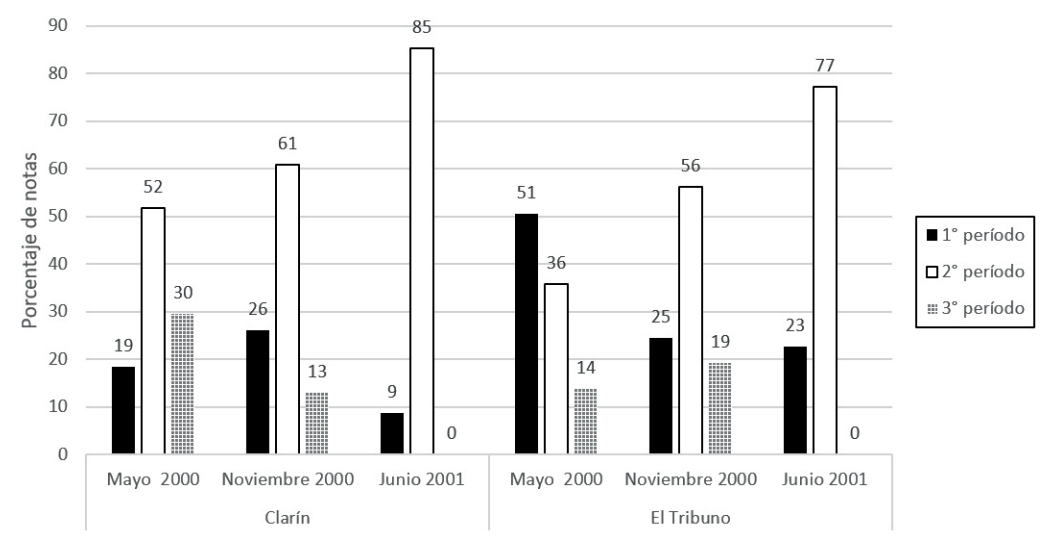

Fuente: elaboración propia con base en las ediciones de Clarín y $E l$ Tribuno (2000-2001).

Durante el primer periodo de las luchas, que como se desprende del Cuadro 1 es el más prolongado, Clarín le otorgó poca importancia al conflicto, absteniéndose de comentarlo en cualquier sentido en varias ediciones. El porcentaje de artículos informativos destinados a dar cuenta de la protesta en su primera etapa osciló en este caso entre el 8 y el $26 \%$ del total de las notas, lo que resulta similar a los números del día que sigue a la resolución del conflicto, que concentró entre el 13 y el 29\% de las notas en un solo día.

En el segundo periodo, que comprendió las acciones represivas y las puebladas, se concentraron el grueso de las noticias del diario nacional, y fue el momento en que los sucesos llegaron a la portada. Este hecho se vincula indudablemente al carácter de los propios acontecimientos en este periodo, que involucraron verdaderas noticias en el sentido de novedades relevantes de la realidad política que, siguiendo los más elementales criterios periodísticos, deben informarse y destacarse. Por otra parte, hay que señalar que 
el propio carácter de periódico nacional le impide a Clarín, por una cuestión de espacio, dar cuenta con detalles de todos los conflictos que estallan en el país.

Con todo, el hecho de que más de la mitad de las noticias se agolpen en entre uno y cuatro días del segundo periodo de cada conflicto habla de una construcción de lo noticiable basado en criterios de espectacularidad. Una protesta que impone durante varios días la interrupción del tránsito en una ruta nacional no deja de ser un acontecimiento político relevante, que podría ser objeto de numerosos artículos periodísticos. De hecho, ese es el caso de El Tribuno en el corte de ruta de mayo de 2000, que publicó la mitad de sus notas en el primer periodo. Esto puede entenderse si se tiene en cuenta el carácter provincial de este último periódico, lo que lo convierte, en principio, en un medio que informa, con respecto a Clarín, sobre una mayor cantidad y variedad de acontecimientos acaecidos. Independientemente del alcance de cada diario, un dato que no puede dejar de considerarse es el hecho de que $E l$ Tribuno es propiedad de la familia de Juan Carlos Romero, gobernador de Salta cuando se desarrollaron las luchas en cuestión, lo que incidirá claramente en las orientaciones de las notas que se analizan a continuación.

\section{Voces autorizadas, reclamos y causas del conflicto}

Vinculado al contenido general de los artículos, es pertinente relevar antes que nada qué sujetos tienen voz y con qué frecuencia. La presencia de determinados emisores y la ausencia de otros sugieren actores legitimados para expresarse, por lo que resulta relevante la frecuencia de aparición de voces de los manifestantes, independientemente del sentido que cobran sus palabras en el texto y de la fuerza cuestionada, es decir, de los diferentes referentes del Estado.

\section{6}


Además de los periodistas que intervienen en la redacción de las notas, aparecen los siguientes emisores: funcionarios y legisladores de partidos de Gobierno a nivel nacional o provincial; funcionarios del Poder Judicial (jueces, fiscales, etc.); manifestantes; referentes de la Iglesia; dirigentes sindicales no participantes de las acciones; dirigentes políticos provinciales y/o nacionales no oficialistas; referentes de las fuerzas represivas; otros no manifestantes (vecinos que no participaban de la protesta, entre otros). Tomando el total de notas publicadas a lo largo de cada conflicto, surge la evolución en el caso de Clarín que se plantea en la Gráfica 2.

Gráfica 2. Evolución de la presencia de emisores.

Mayo de 2000-junio de 2001. Diario Clarín

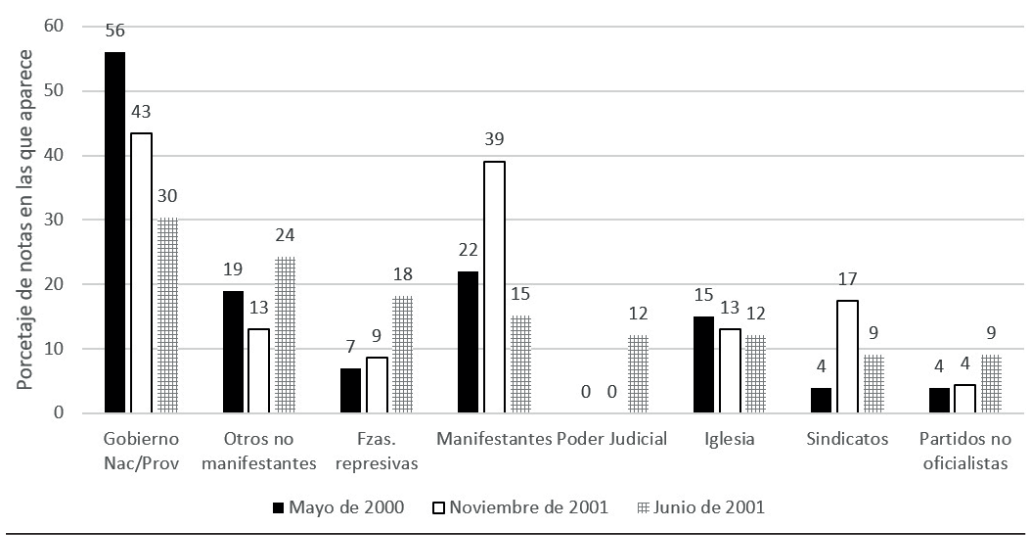

Fuente: elaboración propia con base en las ediciones de Clarín (20002001).

Como se ve, en el caso de las dos primeras protestas, el emisor con mayor presencia fuera del periodista son los funcionarios y legisladores de partidos de Gobierno a nivel nacional o provincial, que intervienen en 56 y $43 \%$ de las notas, seguidos de los manifestantes, que tienen voz en 22 y $39 \%$ de las notas de ese diario. La menor presencia de voces de los manifestantes es esperable tratándose de discursos hegemónicos, en 
particular en momentos en que el orden social está siendo cuestionado. Justamente, lo llamativo es que esa presencia no es para nada marginal en el caso del periódico con mayor influencia del país: nótese que en el conflicto de noviembre de 2000 los manifestantes aparecen en el 39\% de las notas, una frecuencia apenas inferior que la de funcionarios y legisladores oficialistas. Esta constatación se puede dimensionar con más precisión si se comparan estas cifras con las de $E l$ Tribuno, donde los manifestantes figuran tan sólo en 5\% de las notas publicadas durante el conflicto de mayo de 2000 y en $12 \%$ de las correspondientes al de noviembre de ese año.

Ya para el conflicto de junio de 2001 se puede advertir un desplazamiento en Clarín: las notas en las que se expresan directa o indirectamente los manifestantes retroceden a $15 \%$, lo que es menor al lugar cedido a los voceros de las fuerzas represivas, que aparecen en un 18\%. También se agranda la brecha con la presencia de voces de funcionarios y legisladores oficialistas, que ahora duplican a las de los manifestantes. Con todo, la intervención de estos últimos muestra una tendencia decreciente a lo largo de los tres conflictos: del 56\% de mayo de 2000 desciende a $39 \%$ en noviembre y a $30 \%$ en junio de 2001.

Estas modificaciones sugieren dos tendencias: por un lado, a medida que la crisis política y social se va agravando, se va erosionando la legitimidad de los referentes políticos del poder, quienes pierden espacio frente a los manifestantes. Por el otro, cuando esa crisis empieza a amenazar la continuidad del orden político, es decir, cuando se manifiesta como crisis de hegemonía como ocurre hacia mediados de 2001, ambos son desplazados por referentes del aparato represivo y judicial. Este último, de hecho, sólo aparece en el tercer conflicto como emisor.

Adviértase que si en el último conflicto se agregan las voces de funcionarios y legisladores de partidos de Gobierno, funcionarios del poder judicial y referentes de las fuerzas

\section{8}


represivas, es decir, las manifestaciones de las distintas instancias del Estado, se supera el 60\% de intervenciones; la suma de voces de los manifestantes y de quienes actuaron como sus aliados, dirigentes sindicales y políticos opositores, representa poco más de la mitad de la sumatoria de instancias estatales, un 33\% de las intervenciones que tienen espacio en los artículos informativos. Por su parte, las intervenciones de los manifestantes son superadas en el tercer conflicto por las de "otros no manifestantes", que ganan terreno como sujetos capaces de dar testimonio de lo ocurrido.

Otra cuestión relevante es el momento específico dentro de cada protesta en que se da o se niega espacio a los distintos actores, en particular a los protagonistas de la lucha. Esto puede apreciarse en la Gráfica 3.

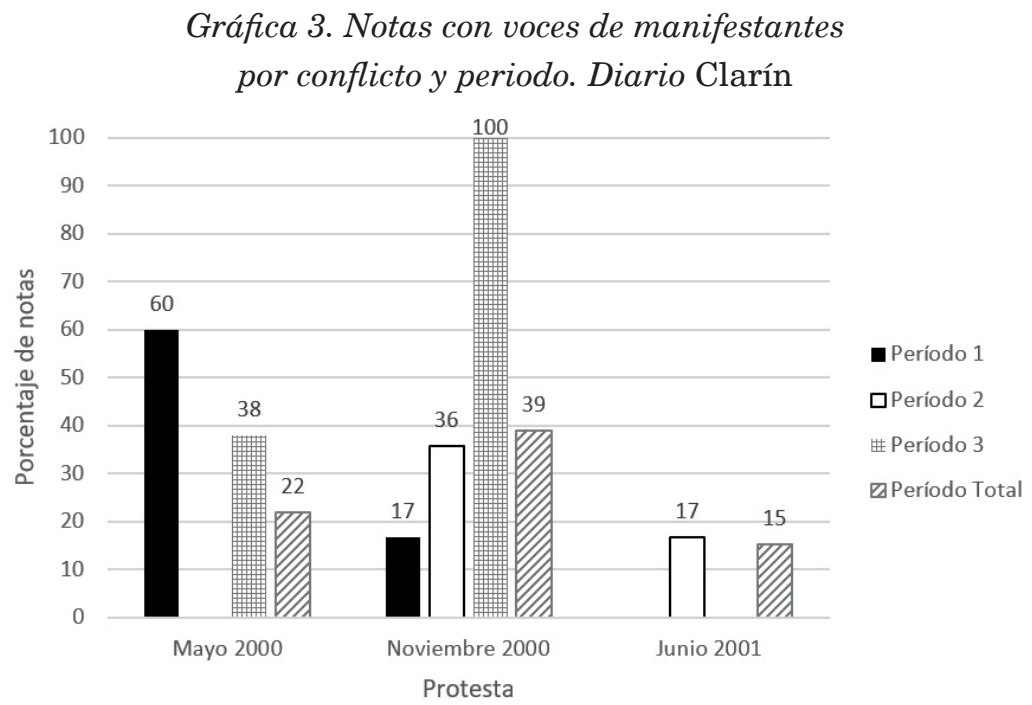

Fuente: elaboración propia en base a las ediciones de Clarín (2000-2001). 
En la primera protesta, llama la atención que en el momento de la rebelión popular, es decir, en el periodo dos, ningún artículo de Clarín recoge ni se interesa por los planteamientos de los manifestantes. Coincidentemente, El Tribuno, poco proclive a otorgar espacio para la voz de estos últimos, también les niega toda posibilidad de expresión durante el segundo periodo de mayo de 2000, cuando protagonizan las acciones más radicalizadas. En contraste con lo anterior, Clarín habilita la voz de los manifestantes en el 60\% de las notas del primer periodo, cuando es de esperar que se informe sobre las causas de la protesta.

Este rasgo de los discursos que produce y reproduce el principal diario del país no se repite en las siguientes luchas. Las intervenciones de los protagonistas de las protestas durante el primer periodo disminuyen abruptamente en noviembre de 2000 y desaparecen en junio de 2001. En cambio, sus voces aparecen en estas dos últimas protestas en los días signados por la represión y la rebelión popular, de las que habían sido excluidos en mayo de 2000. Finalmente, es notorio que todas las notas del día posterior a la firma del acuerdo en noviembre de 2000 incorporan intervenciones de los manifestantes.

De conjunto parece verificarse un corrimiento temporal de las intervenciones de los manifestantes, que puede vincularse a la evolución de la crisis de hegemonía. Las voces que aparecen durante los primeros días de la protesta de mayo de 2000, capaces de justificar los motivos de la medida de lucha, tienden a silenciarse en los conflictos posteriores, pero en la medida en que desafían exitosamente a un régimen político en crisis recuperan posiciones en las siguientes etapas de las protestas; en este sentido, los discursos hegemónicos dan cuenta de la propia crisis de hegemonía. Se revisará esta hipótesis a la luz de otros elementos del contenido general de los artículos periodísticos. 
Desde el punto de vista de las representaciones de los manifestantes y sus acciones, la mención en los artículos de los reclamos que se efectúan y de las causas que originan el conflicto, más allá de cuáles sean específicamente, contribuye a crear una visión legitimante o deslegitimante del conflicto: la enumeración de medidas de fuerza desprovistas de reclamos y de causas explícitas favorece una representación de acciones inmotivadas, sin justificación.

En este sentido, es pertinente examinar entre las notas del corpus cuántas mencionan reclamos de los manifestantes y cuántas mencionan las causas sociales e históricas del conflicto. En este último ítem, se trata de indagar, primero, si más allá de las reivindicaciones de los manifestantes los artículos incluyen una interpretación de tipo social o histórica que contribuya a contextualizar el conflicto.

Es decir, aun dando cuenta de lo que reclaman los manifestantes, los propios reclamos pueden aparecer como injustificados si no se presentan, a su vez, las causas profundas que intervienen para que se formulen las reivindicaciones del caso. La sistematización de la cantidad de notas con y sin mención de reclamos y de causas sociales y/o históricas en el diario Clarín, teniendo en cuenta los distintos periodos, arrojó los resultados que se muestran en la Gráfica 4 y Gráfica 5. 
Gráfica 4. Evolución de la mención de reclamos de los manifestantes. Mayo 2000-junio 2001. Diario Clarín

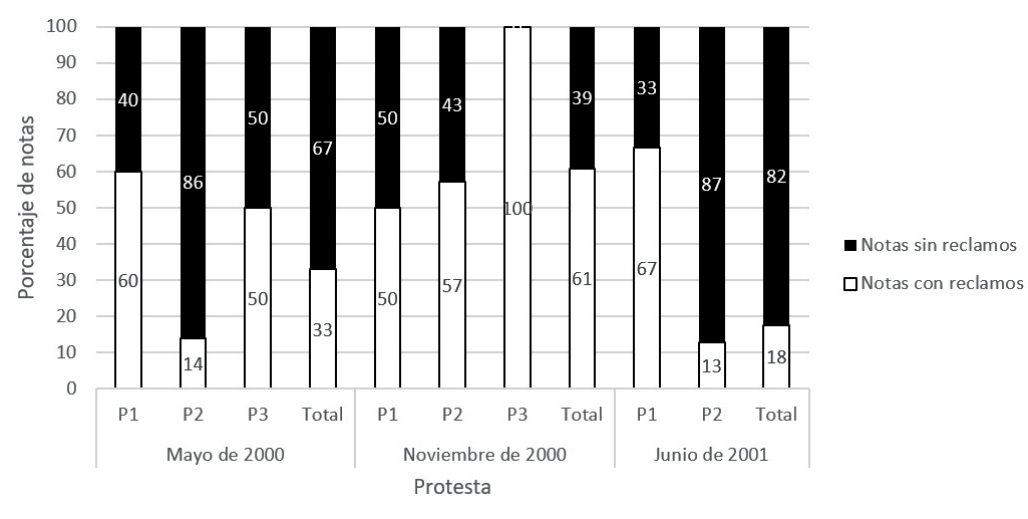

Fuente: elaboración propia con basen en las ediciones de Clarín (20002001).

Gráfica 5. Evolución de la mención de las causas histórico-sociales de la protesta. Mayo 2000-junio 2001. Diario Clarín

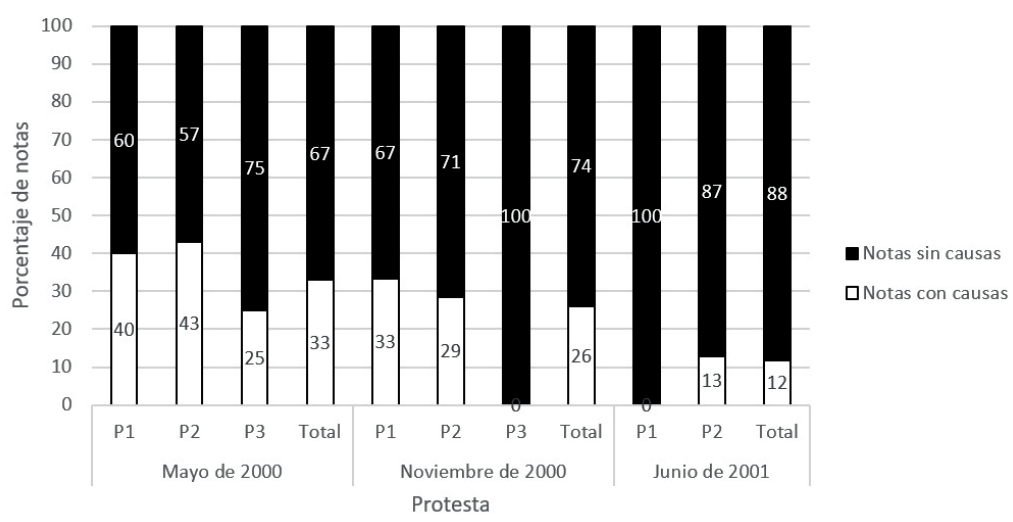

Fuente: elaboración propia con base en las ediciones de Clarín (20002001).

En la protesta de mayo de 2000, sólo un tercio del total de las notas incluyen reclamos de los manifestantes, y otro 
tanto sucede con la mención de causas sociales o históricas del conflicto. En un análisis por periodos, se ve que durante la primera etapa del conflicto en la mayoría de las notas (60\%) constan reclamos, proporción que se reduce drásticamente en la siguiente etapa (14\%). En principio, es posible atribuir este hecho a un desplazamiento del centro de interés con bases objetivas: el segundo momento es el de la pueblada, por lo que la atención se centra en los nuevos acontecimientos que se registraron, es decir, la represión, el ataque a símbolos del poder económico y político y el enfrentamiento con las fuerzas del orden. Teniendo en cuenta que la proporción de notas con consideraciones acerca de las causas de la protesta se mantiene, se puede concluir que el cambio de énfasis en la mención de reclamos no altera la representación de una protesta con reclamos y causas que contribuyen a contextualizarla y legitimarla.

El momento inmediatamente posterior al acuerdo muestra una recuperación de las notas con mención de reclamos, que alcanzan la mitad del total, y la disminución de los artículos que incluyen causas sociales y/o históricas de la lucha. En este caso hay un nuevo corrimiento del foco: la resolución del conflicto requiere de la presencia de artículos que den cuenta de las concesiones realizadas a tal fin, las que necesariamente involucran las reivindicaciones de los manifestantes.

La escasa mención de causas de origen en esta etapa viene a reforzar la idea de resolución del conflicto: si constaran causas como la pobreza o el desempleo -que figuran entre las más aludidas-, quedaría en evidencia que el conflicto no se ha solucionado realmente. Otro efecto de la escasa presencia de causas en esta etapa puede ser el reforzamiento discursivo de la efectividad del método de lucha, que en este periodo se generalizó en todo el país. Es razonable pensar que en un escenario de acuerdo que involucra y visibiliza concesiones, el borrado de las causas que impulsaron a los 
sujetos a la acción favorece la asociación entre método de lucha y obtención de reivindicaciones, más allá de motivaciones que justifiquen o no las acciones.

Con relación a la presencia de reclamos, las tendencias señaladas para la protesta de mayo de 2000 se profundizan en noviembre de 2000, cuando se incrementa el porcentaje de notas con ese contenido en el segundo y tercer periodos, involucrando más de la mitad y la totalidad de las notas respectivamente.

La mención de causas, en cambio, tiende a retroceder levemente en los primeros periodos, para desaparecer completamente en el tercero, lo que provoca un retroceso de un tercio de las notas totales en mayo de 2000 a un cuarto en noviembre de ese año. Ya para 2001 se advierte un quiebre: las notas con mención de reclamos alcanzan su punto más alto en el primer periodo (67\%), pero se reducen drásticamente en el segundo (13\%), sin que eso se vea compensado por una mención relevante de causas, ausente en el primer periodo y mínima en el segundo (13\%).

De conjunto, se encuentran en junio de 2001 menciones de reclamos en un $18 \%$ de las notas y de causas tan sólo en $12 \%$. El elevado porcentaje de presencia de reclamos en el primer periodo debe leerse a la luz de la escasez de notas: como surge del Cuadro 1, Clarín publicó tan sólo tres artículos informativos sobre la protesta a lo largo de dieciocho días, dos de los cuales mencionan los reclamos de los manifestantes. Visto así, la mención de reclamos es insignificante en todos los periodos del conflicto de junio de 2001, y lo mismo ocurre con la mención de causas. En este sentido, se registra un desplazamiento en los discursos tendiente a minimizar causas y reclamos que contribuye a la construcción de una representación deslegitimante de la protesta social, en momentos en que la crisis de hegemonía se encamina a su punto más elevado. 
Hasta aquí, se han revisado los aspectos formales y los contenidos generales de los artículos periodísticos sobre el tema. En el siguiente apartado, se examinan las representaciones específicas que fueron puestas en circulación.

\section{Representaciones sobre las protestas y los manifestantes}

Las representaciones sobre los manifestantes y sus acciones tienen un sentido específico que surge de la combinación de frases dentro de cada nota. Esta combinación da lugar a proposiciones que delinean la táctica discursiva que se desprende del texto. De ahí que a fin de reponer las diferentes representaciones puestas en circulación, fue menester realizar un análisis exhaustivo de cada una de las notas que componen el corpus.

Para el caso de la protesta de mayo de 2000, se reconstruyeron en los artículos de Clarín treinta y seis proposiciones sobre los manifestantes o sus acciones; para el de noviembre de 2000, treinta y ocho; y para el de junio de 2001, treinta y cuatro. Esas proposiciones fueron agrupadas en cinco conjuntos diferentes. Los dos primeros reúnen representaciones de tipo negativas, los dos que siguen positivas, y el quinto corresponde a proposiciones indefinidas. En ese orden, se distinguen primero las representaciones que sugieren que se trata de una protesta impropia o excesiva. Algunos ejemplos de este grupo son los siguientes:

Un hombre de gruesos bigotes descansa en su camión, que desde el martes 2 quedó varado en el corte: debía entregar unos hornos panaderos en Cochabamba (Bolivia). "Avisé a mi familia que estoy inmovilizado. Pero no puedo hacer nada por seguir el viaje. Hay más de 400 camioneros perjudicados", relató (Clarín, 2000a, p. 16).

Ayer a los 70 desocupados que cortan la ruta se le[s] sumaron unos 20 manifestantes aborígenes que agregaron a sus reclamos un petitorio 
de 80 puntos [...]. El acuerdo establecía que los planes Trabajar para desocupados de Tartagal se mantengan a lo largo del 200I. Pero a los manifestantes les pareció insuficiente y decidieron mantener el corte en la ruta (Clarín, 2000b, p. II).

En el primer ejemplo, se colocan en primer plano los perjuicios que genera el corte de ruta a otros sectores de la sociedad, de modo tal que quienes podrían ser pensados como víctimas del desempleo aparecen como responsables de acciones impropias que afectan a otros sujetos, en lugar de enfatizar, por ejemplo, los motivos que llevaron a los manifestantes a impulsar la acción de lucha. La construcción de esta representación negativa se refuerza semánticamente abundando en detalles relativos al perjuicio provocado por los manifestantes.

En el segundo ejemplo, los manifestantes aparecen formulando reclamos excesivos, al punto tal que habría casi un reclamo distinto por cada manifestante. La oferta del Gobierno aparece aquí como razonable, por lo que sólo puede parecer insuficiente a los ojos de sujetos que se han excedido en sus reclamos.

El segundo grupo corresponde a las proposiciones que presentan a los manifestantes como sujetos violentos, propulsores de acciones ilegales y/o como delincuentes. A continuación algunos ejemplos entre los más comunes:

Fuentes de Gendarmería informaron que hace pocos días tuvieron información de que un grupo de piqueteros, al mando de un hombre armado con un rifle cobraba en caminos alternativos un derecho de circulación (Clarín, 2000b, p. II).

[...] la empresa Refinor, cuyos abogados venían pidiendo al juez federal de Salta Abel Cornejo que resguardara la seguridad en sus instalaciones. Allí se almacenan varios millones de litros de petróleo que se temía que pudieran ser robados por los manifestantes (Clarín, 200 la, p. 5). 
En el primer ejemplo de este grupo se combina la construcción de los manifestantes como extorsionadores, con la idea de que parte de ellos están armados, por lo que aparecen como sujetos sumamente violentos y peligrosos. Esta proposición aparece en el mismo artículo que plantea el carácter excesivo de los reclamos de los manifestantes, por lo que se trata de un discurso que propone una representación negativa en múltiples sentidos.

En el segundo ejemplo se asocia a los manifestantes con delincuentes comunes. El propio texto da a entender que la posibilidad de un robo es un temor de la gerencia de la empresa petrolera, y aun así el redactor utiliza la frase impersonal "se temía que pudieran ser robados", lo cual opera generalizando ese temor y otorgándole credibilidad.

Pasando a las proposiciones que formulan representaciones de tipo positivo, se pueden diferenciar las que tienden a justificar la protesta de aquellas que valoran positivamente a los manifestantes, como ocurre respectivamente en los fragmentos que siguen:

[...] la zona está azotada por la falta de trabajo y la pobreza [...] la policía provincial reprimió brutalmente y se retiró [...] la gente enardecida quemó edificios en General Mosconi (Clarín, 2000c, p. I).

Cada uno de los dos piquetes que cortaban la ruta 34 tenían una cabeza visible; pero las asambleas fueron permanentes $y$ todas las decisiones se discutieron intensamente (Clarín, 2000d, p. 9).

En el primer ejemplo, la acción violenta de los manifestantes aparece ampliamente justificada por la represión totalmente desmedida sobre una población desamparada. El uso de la palabra "gente" en lugar de "piqueteros o "manifestantes" refuerza el efecto justificatorio, sugiriendo que cualquier persona en esa situación podría haber actuado de ese modo. 
En el segundo, se presenta a los manifestantes como sujetos democráticos; la atenuación de esto último en la referencia a las "cabezas visibles" refuerza el sentido contrario, que es el propuesto por el texto: las decisiones son colectivas y ampliamente debatidas, no se trata de manipulación ni de caudillismo.

Finalmente, hay notas que se refieren a los manifestantes o a sus acciones, aunque no sea posible determinar una dirección precisa. Un ejemplo de ello se puede encontrar en el fragmento que sigue:

La supuesta existencia de activistas armados en el piquete de General Mosconi generó ayer una serie de especulaciones desde diversos ámbitos sobre la real dimensión de la cuestión (Clarín, 200 Ib, p. 8).

Teniendo en cuenta que las autoridades afirman que hay activistas armados, es claro que el texto pone en duda tal información, evitando así una representación negativa de los manifestantes. Sin embargo, esa posibilidad tampoco se descarta por completo, lo que permitiría una representación positiva. Estos casos fueron considerados ambiguos.

Partiendo de esta clasificación por grupos de representaciones, se obtuvieron los resultados que se muestran en la Gráfica 6.

En dicho gráfico se pueden advertir dos tendencias continuas entre mayo de 2000 y junio de 2001, una de descenso y otra de ascenso. La primera se verifica con relación a las justificaciones de la protesta, que pasan de $39 \%$ al inicio del proceso de luchas bajo análisis a $21 \%$ en el contexto de la última. Pero al contrario de lo que se podría suponer, las representaciones negativas no tienden a incrementarse, sino más bien a caer después de alcanzar un pico en la protesta de noviembre de 2000. Lo que se observa, en cambio, es una tendencia continua de incremento de las notas con proposiciones indefinidas, que de estar ausentes en la pri-

\section{8}


mera acción de lucha llegan a 13\% en la segunda y alcanzan un $44 \%$ en junio de 2001 , la proporción más importante registrada entre todas las categorías de las tres protestas.

Gráfica 6. Evolución de los distintos tipos de representaciones sobre los manifestantes y sus acciones. Mayo 2000-junio 2001.

\section{Diario Clarín}

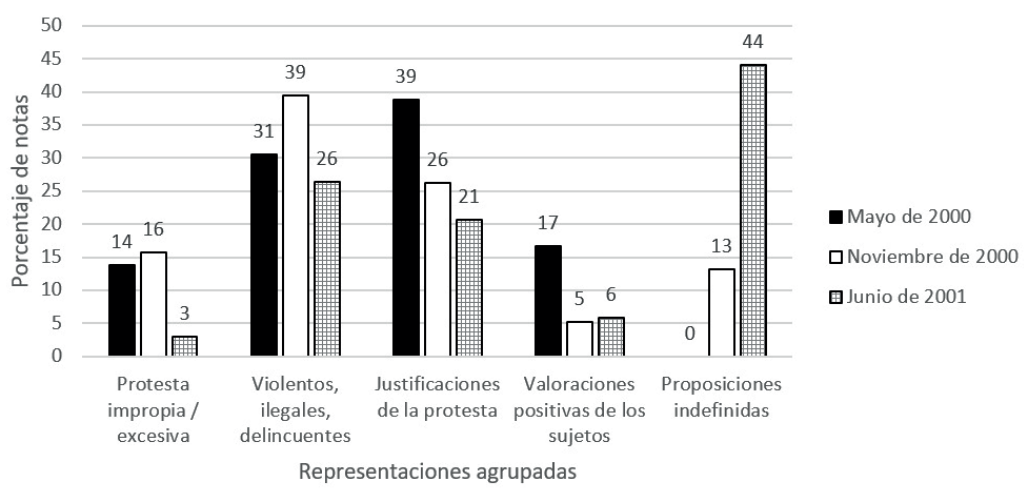

Fuente: elaboración propia con base en las ediciones de Clarín (20002001).

En noviembre de 2000 se nota un cambio con relación al mes de mayo de ese año. El hecho de que disminuyan las representaciones positivas y avancen las negativas sugiere una nueva estrategia de representación que favorece la deslegitimación de los manifestantes. Así, se refuerzan elementos que ya tenían presencia en la primera lucha aunque con menor peso relativo: las ideas de que la protesta es impropia o desmedida y de los manifestantes como sujetos delictivos y violentos avanzan al tiempo que disminuyen las justificaciones y las valoraciones positivas de los protagonistas de la lucha.

Interesa señalar en este punto que esa estrategia no parece haber perdurado: para junio de 2001, las representaciones negativas que se habían fortalecido se debilitan 
nuevamente, junto a los discursos capaces de legitimar las acciones colectivas en cuestión. El incremento paralelo de los artículos con proposiciones indefinidas sugiere nuevamente el advenimiento de la crisis orgánica, donde los discursos hegemónicos pierden claridad, al tiempo que se licúan las bases consensuales del orden dominante.

La misma impresión surge de considerar el conjunto de artículos publicados a lo largo del proceso de luchas de acuerdo a su posición predominante (Gráfica 7).

\section{Gráfica 7. Notas con representaciones de los manifestantes} según posición predominante, por periodo. Mayo de 2000-junio de 2001. Diario Clarín

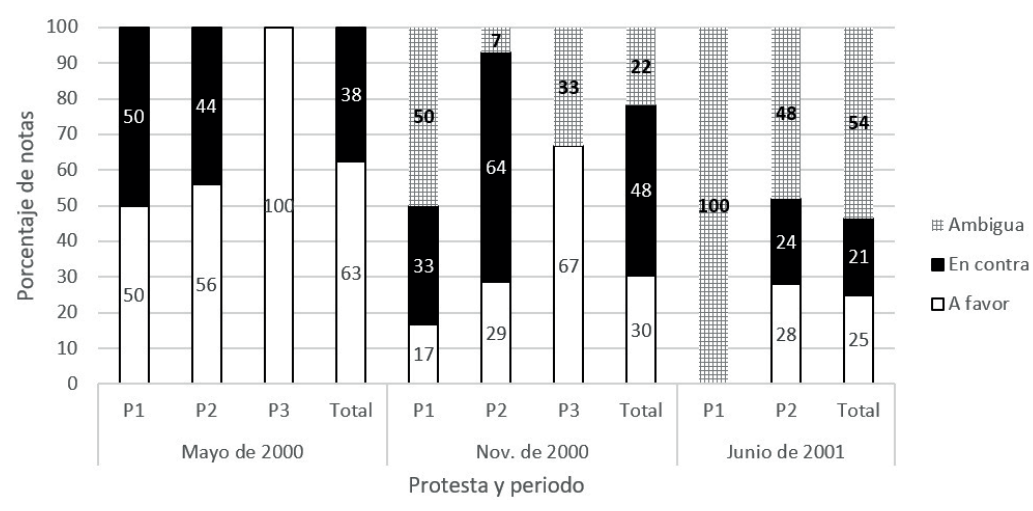

Fuente: elaboración propia con base en las ediciones de Clarín (20002001).

En mayo de 2000, las notas predominantemente en contra de los manifestantes en ningún periodo superan el 50\% de las publicadas en Clarín, configurando una virtual paridad con los artículos predominantemente favorables durante los dos primeros momentos. En este sentido, las tendencias principales del discurso de Clarín durante el conflicto no se ubican en el terreno de la demonización de los manifestan- 
tes, sino que tienden a justificar sus motivos. El hecho de que la totalidad de los artículos publicados una vez que el conflicto fue desactivado tenga un posicionamiento general favorable ante los manifestantes refuerza esa perspectiva.

Considerando los totales, se puede observar que los artículos que adoptan una posición predominantemente a favor de los manifestantes y sus acciones tienden a disminuir a lo largo del proceso de luchas 2000-2001, lo que indica una modificación en las estrategias discursivas que tiende a socavar la posición de estos últimos. Ahora bien, atendiendo a la primera y a la última protesta, llama la atención que también disminuyen las notas que se caracterizan por presentar un contenido mayormente opuesto. En cambio, las notas ambiguas, inexistentes en la protesta de mayo de 2000 , son más de la mitad en junio de 2001, confirmando la impresión señalada más arriba.

Si se observa el tipo de nota que predomina en los distintos periodos de cada protesta, se ve el mismo avance de las notas ambiguas, particularmente en el primer periodo, cuando la lucha no alcanza su punto de mayor conflictividad. De un equilibrio entre notas predominantemente positivas y negativas al comienzo de la primera protesta, se pasa a una presencia de un 50\% de notas ambiguas en la segunda, y a un $100 \%$ en la tercera. En la protesta de noviembre de 2000, cuando se produce la pueblada, las ambigüedades ceden algo de terreno a las notas negativas. Sin embargo, al igual que en mayo de ese año, estas últimas desaparecen el día posterior a la firma del acuerdo. En este punto, la diferencia entre ambas protestas es que en mayo de 2000 se encuentra que la totalidad de las notas publicadas en el tercer periodo son de tendencia positiva, mientras que en noviembre de 2000 esa unanimidad está debilitada por las notas ambiguas.

Se observa ahora cuál es el contenido específico de las representaciones propuestas en cada etapa. Como se des- 
prende del Gráfico 6, si se exceptúan las proposiciones indefinidas, los grupos de categorías con mayor presencia en todos los conflictos son los que construyen a los manifestantes como violentos, ilegales o delincuentes, y el que contiene distinto tipo de justificaciones de la protesta. Estos grupos pueden desagregarse en las proposiciones manifestadas en el Cuadro 2.

\section{Cuadro 2. Proposiciones desagregadas de los grupos de representación más frecuentes}

Violentos, ilegales, delincuentes

Violentos en general

Violentos-vándalos

Violentos-armados-peligrososagresores

Subversivos-armados

Delincuentes-ladrones

Delincuentes-responsables de acción ilegal

Infiltrados

Extorsionadores
Justificaciones de la protesta

Víctimas del desempleo-reclamos legítimos

Víctimas del desempleo-protesta justificada

Víctimas de exceso represivo

Enfurecidos por represión brutal

Protagonistas de protesta comunitaria masiva

Desoídos-ignorados por las autoridades

Fuente: elaboración propia con base en las ediciones de Clarín (20002001).

Cabe aclarar que en el diseño de estas categorías se buscó establecer el mayor nivel de especificidad posible respetando los contenidos de las notas. Siguiendo este criterio, en la primera columna del Cuadro 2 se listan las distintas representaciones asociadas al agregado "Violentos, ilegales, delincuentes". El tópico "violentos", en los casos en que se presenta, se desagrega según los diferentes tipos de violencia asignados a los manifestantes, que aparecen como vándalos, armados-peligrosos-agresores o como una 
fuerza de choque. Se utiliza la representación "Violentos en general" cuando las significaciones no se ajustan a ningunas de las otras categorías listadas del tópico "violentos". Con relación al ideologema "subversivo", fuertemente vinculado a la represión estatal y paraestatal de los años setenta, se optó por distinguirlo de los anteriores. Por su parte, se especifica la figura "delincuente" según se vincula a los manifestantes con acciones de robo o a la propia iniciativa de bloquear la ruta, que es considerada ilegal. Las últimas dos representaciones se vinculan a la idea de que hay infiltrados entre los manifestantes, generalmente agentes externos con relación a la sociedad local que se montan sobre la protesta y que alientan la violencia, y la idea de que los manifestantes aprovechan la oportunidad para extorsionar a quienes esperan atravesar el corte de ruta.

En la segunda columna del Cuadro 2 se enlistan las diferentes representaciones tendientes a justificar la protesta. La representación de los manifestantes como víctimas del desempleo o la pobreza opera legitimando reclamos o justificando la acción de lucha en los dos primeros casos, y en el tercero y cuarto la represión desmedida de las fuerzas de seguridad tiende a justificar el estallido de las puebladas. Las ideas de que se trata de protestas comunitarias de carácter masivo y de que los manifestantes no han sido escuchados por las autoridades contribuyen a su vez a legitimar las acciones de lucha. Dicho esto, en la Gráfica 8 se observa cuál es el peso relativo dentro del grupo de representaciones vinculadas a la figura "Violentos, ilegales, delincuentes". 
Gráfica 8. Peso relativo de las proposiciones vinculadas a la figura "Violentos-ilegales-delincuentes". Mayo de 2000-junio de 2001. Diario Clarín

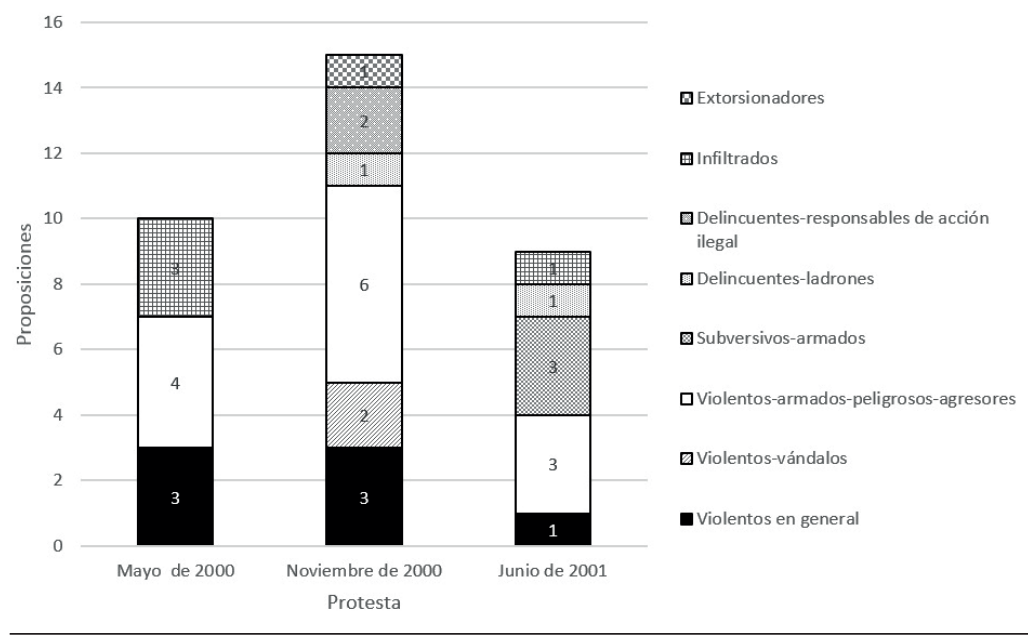

Fuente: elaboración propia con base en las ediciones de Clarín (20002001).

Lo primero que salta a la vista en dicho gráfico es la diversificación de representaciones que se produce después de la primera protesta. Entre las representaciones ausentes en mayo de 2000 que aparecen en noviembre de ese año, se encuentran la del vandalismo, la del delincuente común, la de la extorsión y la de sujetos que actúan ilegalmente por el hecho de bloquear la ruta. Eso no implica, sin embargo, un debilitamiento de la representación de los manifestantes como sujetos violentos, armados y peligrosos, que es la que aparece dentro del grupo analizado con mayor frecuencia en todas las protestas.

Es pertinente destacar a su vez que en junio de 2001 se formula una nueva representación que ocupa junto a la anterior el primer lugar en cuanto a repeticiones: la de subversivos-armados. La construcción de los manifestantes como sujetos armados y peligrosos parece aquí dar lugar a 
una proposición más exacerbada, recurriendo a la figura del subversivo. Llama la atención el hecho de que esta última aparezca en Clarín recién en 2001, porque en el caso de El Tribuno está presente desde la primera protesta. ${ }^{9}$ Lo mismo ocurre en el caso del periódico salteño con las representaciones de los manifestantes como extorsionadores, violentos-vándalos, violentos-combatientes, delincuentesresponsables de acción ilegal y delincuentes-ladrones, desplegadas en sus páginas desde mayo de 2000 (Benclowicz y Werenkraut, 2013).

Con relación a la diversificación de representaciones negativas, es posible pensar que se pasa de un primer momento de relativa certeza acerca de qué es lo que ocurre en las descripciones de Clarín, a un mayor grado de indefinición en la segunda protesta, que deriva en la adopción de sentidos que ya circulaban en otros diarios, pero que Clarín se guardó inicialmente de reproducir. Aquí se expresa, más allá de la línea editorial, la tendencia a la formación de una estrategia general de los discursos dominantes, producida y reproducida por los medios masivos, que intervienen en un contexto de auge de las organizaciones de desocupados, procurando minar su legitimidad (Zullo, 2010).

Evidentemente, algo ocurrió hacia mediados de 2001 que llevó al periódico más leído del país a incorporar una representación vinculada a la profunda impugnación del orden social que se registró durante la década de 1970. Así es que los piqueteros, que se cuentan entre los luchadores más radicalizados en los albores del siglo XXI, son pensados, ante la profundización de la crisis del orden político, como los impugnadores radicales del pasado reciente. De un modo

9. Por ejemplo, en mayo de 2000 este diario aseguró que "Aparecieron armas, bombas molotov y encapuchados [...] un grupo penetró por la fuerza en la planta de Refinor y roció con nafta los tanques con derivados de gas y petróleo" (EI Tribuno, 2000, s/p). 
específico, la evolución de las principales representaciones positivas acompaña ese movimiento (Gráfica 9).

Gráfica 9. Peso relativo de las representaciones vinculadas a justificaciones de la protesta. Mayo de 2000-junio de 2001. Diario Clarín

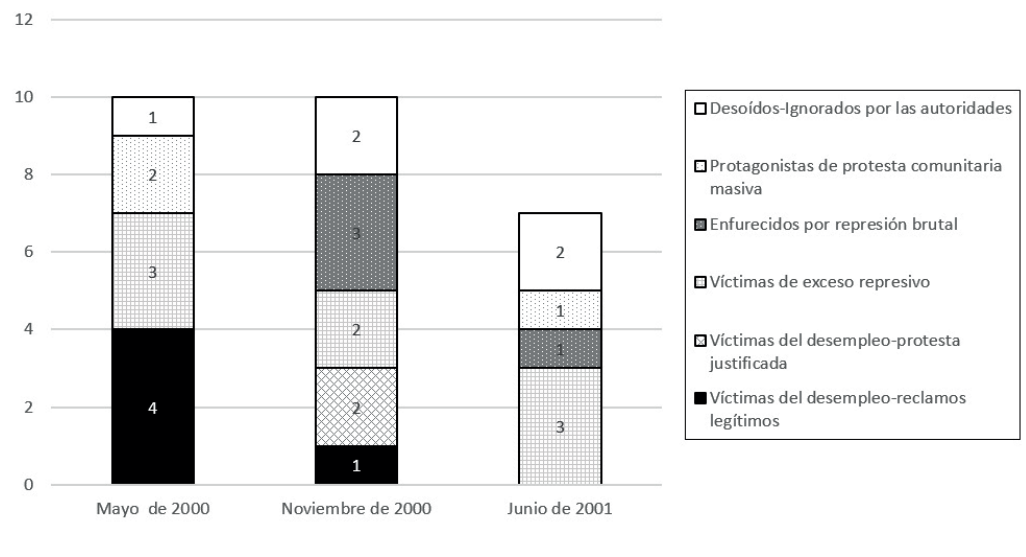

Fuente: elaboración propia con base en las ediciones de Clarín (20002001).

Como se puede ver, las justificaciones más estructurales que se despliegan en mayo y noviembre de 2000 -la construcción de los manifestantes como víctimas del desempleo y la presentación de la protesta como una consecuencia de este último- desaparecen en junio de 2001. Los planteamientos esgrimidos, de carácter coyuntural, indican un cambio cualitativo en función del cual el frágil orden imperante ya no es puesto en cuestión: si se justifica parcialmente a los manifestantes ya no es por sus propios derechos, sino por los excesos de las fuerzas represivas y por la falta de disposición al diálogo de las autoridades, todo lo cual apunta a la reconstrucción de las bases consensuales del poder. De hecho, como se vio en el Gráfico 5, en esta última protesta se alcanza el récord de $88 \%$ de artículos en los que no se 
mencionan causas sociales o históricas de la lucha. En ese escenario, la violencia de unos y otros emerge como el elemento explicativo más poderoso de lo que ocurre. De este modo se recurre una vez más a una estrategia discursiva fuertemente instalada desde los años setenta, en la que dos agentes violentos victimizan a una sociedad inocente.

Hasta cierto punto, es posible pensar que a nivel local semejante estrategia fue exitosa; de hecho, después de junio de 2001 ya no se registraron protestas de la misma envergadura, y la valoración negativa del movimiento piquetero en Tartagal y Mosconi se acrecentó (Benclowicz, 2011b). Con todo, el crecimiento sostenido de la izquierda radicalizada en Salta, asociada a las luchas piqueteras, ilustra los límites de esa estrategia. ${ }^{10}$ Más allá de eso, las representaciones sobre las puebladas del norte de Salta jugaron un papel relevante en el proceso de radicalización general a nivel nacional, que alcanzó su punto más alto con la caída del presidente Fernando de la Rúa tras las masivas jornadas del 19 y 20 de diciembre. En este sentido, la estrategia demonizadora fracasó. Las moderadas reformas instrumentadas a partir de 2003 a nivel nacional, que limaron algunas de las aristas del modelo neoliberal, requieren pensarse en el contexto de ese fracaso.

\section{Reflexiones finales}

A lo largo de este trabajo, se examinaron cambios y continuidades en las estrategias discursivas del diario con mayor difusión, y cabeza del principal conglomerado multimedios en Argentina, con relación al proceso de luchas registrado entre mayo de 2000 y junio de 2001 en Tartagal y Mosconi.

10. Tras un crecimiento sostenido, en 2013 el trotskista Partido Obrero llegó incluso a imponerse electoralmente en la capital provincial con un $27 \%$ de los sufragios, obteniendo representantes en todas las categorías y un amplio caudal de votos en todas las localidades. 
A nivel nacional, el periodo registró una creciente radicalización y agudización de los conflictos sociales y la crisis del orden político, que alcanzó su punto más elevado a fines de 2001 con la renuncia del presidente Fernando de la Rúa. Este acontecimiento reviste características inéditas en el país: no existen antecedentes de un proceso de rebelión popular que provoque la caída de un Gobierno elegido democráticamente por amplia mayoría, tan sólo dos años antes.

La relación entre la progresiva radicalización que caracteriza al periodo y las representaciones desplegadas en Clarín sobre las acciones colectivas en cuestión demostró ser compleja y contradictoria: no se trató de una defensa cerrada del orden imperante ni de una demonización lisa y llana de las protestas piqueteras, como pudiera suponerse a priori tratándose de los discursos de uno de los grupos empresarios más influyentes del país, que se venía beneficiando ampliamente con base en el orden ahora impugnado.

Hacia el inicio del proceso, llama la atención la presencia mayoritaria de un conjunto de representaciones favorables a los manifestantes, las cuales tienden a justificar sus acciones. Esto contrasta con la estrategia discursiva de diarios como El Tribuno, que construye un relato criminalizador de los sujetos en lucha. El reclamo por trabajo, derecho que formalmente está consagrado en la Constitución Nacional, fue construido por Clarín como un acto justificado. Es posible pensar que esta tendencia favoreció el desarrollo de otras luchas, que de hecho tendieron a multiplicarse en el periodo. La falta de explicitación al momento de la resolución provisoria de los conflictos de las causas que los motivaron sugiere la idea de una resolución más o menos definitiva de los problemas, que resultó insostenible ante el desarrollo de los acontecimientos, plausiblemente acicateados por la difusión de un método de lucha que aparecía como efectivo más allá de sus circunstancias. 
Para principios del año 2000, el nuevo gobierno de la Alianza contaba con el capital político de una amplia y reciente victoria electoral, aunque la crisis socioeconómica no moderaba su ritmo. A medida que la crisis avanzó y la legitimidad del orden político se licuó, se notaba en Clarín un retroceso sistemático de las representaciones positivas, y para junio de 2001 una tendencia a la invisibilización de las causas de las luchas y los reclamos formulados y la introducción de la representación de los manifestantes como subversivos, propia de la formación discursiva de los años setenta. El gran diario argentino consiente aquí tardíamente reproducir un ideologema que es agitado crecientemente por la Alianza, el PJ y distintos medios de comunicación, cuando comienza a ponerse en cuestionamiento no sólo al Gobierno, sino al propio orden político.

Sin embargo, visto en conjunto, la tendencia decreciente de las representaciones positivas no se ve acompañada por un aumento equivalente de las caracterizaciones negativas, sino que estas últimas también tienden a descender si se considera el proceso en su totalidad (aunque la criminalización se extrema al recurrir a la figura del "subversivo"), y lo mismo ocurre con el espacio que se otorga a las voces de funcionarios y legisladores del régimen.

Se vinculó este hecho a la evolución de la propia crisis política: en la medida en que hacia 2001 las clases dominantes no lograban reproducir su hegemonía sobre la sociedad, los discursos de los referentes políticos del poder perdían peso y cedían terreno a los referentes de los aparatos represivo y judicial, mientras que los propios discursos hegemónicos, en este caso el de los artículos periodísticos más difundidos, perdían su capacidad de interpretar los sucesos y de interpelar eficazmente a la sociedad.

Esto se vincula al carácter relacional de las construcciones hegemónicas, que deben redefinirse permanentemente en función del desarrollo de los distintos acontecimientos 
sociales. En el caso de la prensa masiva, la significación de las luchas no puede divorciarse de otras representaciones sociales relevantes que circulan, asociadas a su vez al curso y carácter que asumen las primeras. Si fuera posible semejante orientación continuada por parte de un medio masivo, este perdería toda credibilidad y sería desplazado por una competencia capaz de ofrecer claves interpretativas coherentes.

Así, los acontecimientos registrados en Tartagal y Mosconi, que figuran entre los principales fenómenos de lucha social en la convulsionada Argentina de la época, son construidos hacia mediados de 2001 con fuertes indefiniciones, que reflejan la incapacidad de desarrollar una estrategia discursiva a un tiempo creíble y disciplinadora. Próximos trabajos deberán ampliar tanto geográfica como temporalmente el estudio de estos discursos, así como indagar de qué modos fueron recepcionados, a fin de analizar con datos concretos su incidencia en el propio proceso de luchas.

Bibliografía

Benclowicz, J. (20I la). "Repensando los orígenes del movimiento piquetero". Latin American Research Review, 46(2), 79-103.

- (20 I lb). "Continuities, scope and limitations of the Argentine picket movement". Latin American Perspectives, I 76(38), 74-87.

(20l3). Estado de malestar y tradiciones de lucha. Argentina: Biblos.

- y Artese, M. (20I I). "Legitimidades enfrentadas: orden político imperante y puebladas en el norte de Salta a comienzos del nuevo milenio". Fundamentos en Humanidades, 22(2), II7-I38.

y Werenkraut, V. (20I3). "Las luchas sociales a través de los medios masivos". Aposta. Revista de Ciencias Sociales, (58), I-43.

\section{0}


Bonnet, A. (2008). La hegemonía menemista. Argentina: Bibliografía Prometeo.

Clarín (I 2 de mayo de 2000a). "Piqueteros en Salta: con la mirada puesta en el sur", p. 16.

(06 de noviembre de 2000b). "Grupos aborígenes se suman a los piqueteros de Tartagal", p. II.

(I I de noviembre de 2000c). "El aluvión de bronca que arrasó Tartagal”, p. I.

( 13 de mayo de 2000 d). "Las cabezas visibles", p. 9. (I8 de junio de 200 Ia). "La visita frustrada el Día del Padre", p. 5.

( 10 de junio de $200 \mathrm{lb}$ ). "Distintas especulaciones sobre el fantasma de grupos armados", p. 8.

Díaz Muñoz, M. (2005). Orden, represión y muerte. Diario de la criminalización de la protesta social en Salta (1995-2005). Argentina: Tierra del Sur y Colectivo La Rabia.

El Tribuno (09 de mayo de 2000). "Se agrava la situación por el corte de la ruta 34", s/p.

Fairclough, N. (1993). Discourse and Social Change. Inglaterra: Polity Press.

Gramsci, A. (200I). Notas sobre Maquiavelo, sobre la política y sobre el Estado moderno. Argentina: Nueva Visión.

Hall, S. (I98I). "La cultura, los medos de comunicación y el “efecto ideológico”'. En J. Curran, et al. (comps.), Sociedad y comunicación de masas (Pp. 357-392). México: FCE. INDEC (200I). Censo Nacional de Población y Viviendas $200 \mathrm{I}$. Argentina: Instituto Nacional de Estadísticas y Censos. Iñigo Carrera, N., y Cotarelo, M. C. (2006). "Génesis y desarrollo de la insurrección espontánea de diciembre de 200 I en Argentina", en G. Caetano (comp.), Sujetos sociales y nuevas formas de protesta en la historia reciente de América Latina (pp. 49-92). Argentina: CLACSO.

Mastrini, G., y Becerra, M. (2006). Periodistas y magnates. Estructura y concentración de las industrias culturales en América Latina. Argentina: Prometeo. 
Bibliografía (20II). "Estructura, concentración y transformaciones en los medios del Cono Sur latinoamericano". Comunicar, 36(XVIII), 5I-59.

Ministerio del Interior (200I). Elecciones nacionales $200 \mathrm{I}$. Argentina: Ministerio del Interior.

Oviedo, L. (200I). Una historia del movimiento piquetero. Argentina: Rumbos.

Piva, A. (20I2). Acumulación y hegemonía en la Argentina menemista. Argentina: Biblos.

Sivak, M. (20I3). Clarín, el gran diario argentino. Una historia. Argentina: Planeta.

Svampa, M., y Pereyra, S. (2003). Entre la ruta y el barrio. Argentina: Biblos.

Van Dijk, T. (1990). La noticia como discurso. España: Paidos. (2008). Ideología. Argentina: Gedisa.

Verón, E. (1993). La semiosis social. España: Gedisa.

Zullo, J. (20I0). Los actores sociales de la pobreza: piquetes y piqueteros en la prensa argentina (1996-2002) (tesis doctoral inédita). Universidad de Buenos Aires: Buenos Aires. 